\title{
Pembinaan Sikap Peduli Sosial Siswa Melalui Kegiatan Pramuka Di SMP Negeri 10 Padang
}

\author{
Nurhidayati, Junaidi Indrawadi \\ Prodi Pendidikan Pancasila dan Kewarganegaraan \\ Universitas Negeri Padang \\ E-mail: Nurhidayatiii36@gmail.com
}

\section{ABSTRAK}

Penelitian ini dilatarbelakangi oleh pentingnya membina kepedulian sosial siswa melalui kegiatan pramuka di SMP Negeri 10 Padang. Kepedulian sosial siswa dimaksudkan terutama dalam mengamalkan nilai-nilai yang terkandung dalam dasa darma pramuka dan aktivitas kepramukaan dalam meningkatkan kepedulian sosial siswa. Jenis penelitian ini adalah kualitatif dengan menggunakan metode deskriptif. Pemilihan informan dilakukan dengan teknik purposive sampling. Informan dalam penelitian ini adalah kepala sekolah, wakil kesiswaan, guru, siswa yang tidak terlibat dan terlibat dalam pramuka. Jenis data adalah primer dan sekunder yang dikumpulkan melalui observasi, wawancara dan studi dokumentasi. Uji keabsahan data dilakukan dengan teknik triangulasi sumber, kemudian data dianalisis dengan cara reduksi data, analisis data, dan penarikan kesimpulan. Penelitian ini menunjukkan bahwa siswa sudah mengamalkan nilai-nilai dasa darma pramuka. Aktivitas dalam setiap kegiatan pramuka dapat membina kepedulian sosial siswa yaitu peduli terhadap sesama, peduli terhadap orang lain dan peduli terhadap lingkungan. Hal tersebut tertuang dalam dasa darma pramuka yang mengandung nilai moral dan sosial. Pembinaan sikap peduli sosial dilakukan dalam berbagai aktivitas dalam setiap kegiatan pramuka seperti: kegiatan upacara, baris berbaris, berkemah, bakti sosial, hiking atau penjelajahan. Kegiatan tersebut dilakukan sesuai dengan dasa darma pramuka sehingga menjadikan siswa berkarakter dan berjiwa sosial yang tinggi.

Kata Kunci: kepedulian sosial, pramuka, dasa darma, karakter

\section{ABSTRACT}

This research is motivated by the importance of fostering the social care of students through scouting in SMP Negeri 10 Padang. Social care is intended primarily in practicing the values contained in the dasa darma and scouting in increasing students social care. This type of research is qualitative using descriptive methods. The selection of informants was carried out using a purposive sampling technique, where the informants in this study were the principal, student representatives, teachers, students who were not involved and involved in scouting. The types of data are primary and secondary collected through observation, interviews and documentation studies. Data validity test is done by using source triangulation technique, then data is analyzed by data reduction, data analysis, and drawing conclusions. This study shows that students have practiced the values of the dasa darma 
Volume 3 No. 12020

pramuka. Activities in every scouting activity can foster students social care that is caring for others and caring for the environment. This is stated in the dasa darma pramuka containing moral and social values. Social care attitude development is carried out in various activities in every scouting activity such as: ceremonial activities, marching lines, camping, social service, hiking or exploring. The activity was carried out in accordance with the scouting precepts to make high social character of students.

Keywords : social care, scouting, dasa darma, character

This work is licensed under the Creative Commons Attribution-ShareAlike 4.0 International License. (2019 by author.

Received: Des $262019 \quad$ Revised: Jan 202020 Accepted: Feb 142020

\section{PENDAHULUAN}

Gerakan Pramuka adalah salah satu pendidikan mendunia yang bebas diikuti oleh semua orang dengan berbagai kegiatan yang menarik, menyenangkan dan menantang. Pendidikan kepramukaan ini sangat tepat dalam membina kepedulian seseorang karena manusia adalah makhluk sosial yang pada hakikatnya mereka tidak bisa hidup sendiri tanpa bantuan orang lain. Untuk mendapatkan bantuan dari orang lain maka manusia harus saling peduli. Manusia sebagai makhluk sosial pada dasarnya tidak terlepas dengan manusia lainnya, sehingga hubungan antara manusia tersebut merupakan suatu kebutuhan yang objektif (Soekanto, 2014:74).

Penelitian terdahulu dalam penelitian ini yaitu Asnawi \&Triwahyuningsih (2014), tentang peranan pembina pramuka dalam mengembangkan karakter kepemimpinan siswa di SMP Negeri 3 Depok, Sleman. Dalam penelitian ini pembina pramuka melibatkan siswa dalam merencanakan program kegiatan, menampilkan sikap dan perilaku yang baik dan memberikan kesempatan yang luas kepada siswa untuk mengekspresikan idenya dalam kegiatan. Penelitian A.Ta'biin (2017) menyatakan bahwa kepedulian sosial penting dimiliki karena terkait dengan nilai-nilai kejujuran, kasih sayang, rendah hati, keramahan dan kebaikan. Selanjutnya penelitian Erliani (2016), menyatakan bahwa upaya pembentukan karakter pada gerakan pramuka SDIT Al-Ukhwah dilakukan dengan pemahaman, keikhlasan, kerja keras, berjuang dengan sungguhsungguh, ketaatan, pengorbanan, komitmen, konsisten, persaudaraan, dan kepercayaan.

Berdasarkan beberapa penelitian terdahulu yang telah dijelaskan diatas maka penelitian ini menfokuskan pada pengamalan nilainilai dasa darma pramuka melalui berbagai aktivitas kegiatan pramuka yang dilakukan di SMP Negeri 10 Padang. Kegiatan pramuka menjadi salah satu pembentuk karakter bangsa diantaranya berjiwa patriot, nasionalisme, cinta kepada Tuhan, cinta kepada sesama, cinta kepada alam, mengajarkan disiplin, mandiri, saling tolong-menolong, saling menghargai, serta peduli antar sesama dan lingkungan. Banyak kalangan termasuk pemerintah menaruh kepercayaan kepada Gerakan 
Pramuka sebagai organisasi pilihan utama dalam membangun karakter dan meningkatkan rasa kepedulian sosial antar sesama. Hal ini dapat melahirkan generasi muda yang berjiwa sosial yang tinggi, memiliki kepekaan dan kepedulian terhadap perkembangan bangsa dan negaranya. Gerakan Pramuka selaku penyelenggara pendidikan kepramukaan mempunyai peran besar dalam pembentukan kepribadian dan kepedulian sosial generasi muda sehingga memiliki pengendalian diri dan kecakapan hidup untuk menghadapi tantangan kehidupan. Dalam kepramukaan itu terdapat dasa darma pramuka yang merupakan ketentuan moral bagi setiap anggota pramuka.

Berdasarkan Keputusan Kwatir Nasional Gerakan Pramuka Nomor 203 Tahun 2009 tentang Anggaran Rumah Tangga Gerakan Pramuka (ARTGP) dan Keputusan Presiden Republik Indonesia Nomor 24 Tahun 2009 Tentang Pengesahan Anggaran Dasar Gerakan Pramuka(ADGR), dasa darma pramuka terdiri dari Taqwa kepada Tuhan yang Maha Esa, cinta alam dan kasih sayang sesama manusia, patriot yang sopan dan kesatria, patuh dan suka bermusyawarah, rela menolong dan tabah, rajin,tampil, dan gembira, hemat,cermat, dan bersahaja, disiplin, berani dan setia, bertanggungjawab dan dapat dipercaya, dan suci dalam pikiran, perkataan dan perbuatan.

Gerakan Pramuka harus mampu mendidik dan membina generasi muda untuk tidak mudah putus asa, pantang menyerah dan dengan penuh keberanian menghadapi berbagai tantangan. Kegiatan kepramukaan menggunakan metode outdoor study, anggota diajarkan untuk dekat dengan lingkungan dan peduli kepada orang lain sebagaimana catatan pendiri pramuka, Baden Powel menyatakan bahwa menjadi orang baik tidak hanya selalu berdo'a tapi bagaimana berusaha keras untuk berbuat baik dan peduli pada orang lain (Erliani, 2016 : 37).

$\begin{array}{rlrr}\text { SMP } & \text { Negeri } & 10 & \text { Padang } \\ \text { merupakan } & \text { salah } & \text { satu } & \text { Sekolah }\end{array}$
Menengah Pertama yang aktif dalam melaksanakan kegiatan pramuka. Kegiatan pramuka di SMPN 10 Padang sudah terlaksana dengan baik. Namun dalam pembinaan sikap kepedulian sosial siswa masih sangat rendah. Pada saat sekarang ini sikap dan rasa kepedulian seseorang terhadap penderitaan orang lain sudah mulai luntur terutama pada kalangan anakanak bahkan generasi muda yang pada saat ini hanya disibukkan dengan aktivitas masing-masing tanpa adanya interaksi atau tegur sapa. Hal tersebut salah satunya dipengaruhi oleh perkembangan teknologi seperti gawai (gadget), dimana mereka sibuk dengan gawai masing-masing. Dari pada itu, untuk menumbuhkan rasa kepedulian seseorang, diperlukan adanya pembinaan dan pembiasaan yang terus menerus agar menjadi suatu kebiasaan. Kepedulian harus dibina sejak dini agar kelak mereka menjadi orang yang berguna bagi keluarga, masyarakat, bangsa dan negaranya. Salah satu kegiatan yang dapat memberikan pendidikan dan pembinaan bagi setiap orang adalah melalui kegiatan pramuka atau pendidikan kepramukaan.

Tujuan penelitian ini adalah untuk mengetahui kepedulian sosial siswa dalam mengamalkan dasa 
darma pramuka dan untuk mengetahui aktivitas nilai-nilai dasa darma dalam meningkatkan kepedulian sosial siswa. Penelitian ini juga memberikan manfaat bagi seluruh pihak baik itu sekolah, siswa, guru dan masyarakat sekitarnya, dimana dengan penelitian ini dapat memberikan pengetahuan dan pemahaman bahawa dalam kegiatan pramuka banyak sekali memberikan pembelajaran dan pembinaan karakter bagi siswa dengan selalu mengamalkan nilai-nilai dasa darma pramuka dalam kehidupan seharihari. Berdasarkan latar belakang masalah diatas maka peneliti tertarik untuk melakukan penelitian mengenai pembinaan sikap peduli sosial siswa melalui kegiatan pramuka di SMP Negeri 10 Padang.

\section{METODE PENELITIAN}

Jenis penelitian ini adalah kualitatif dengan metode desriptif, dengan tujuan untuk menjelaskan pembinaan sikap peduli sosial siswa melalui kegiatan pramuka di SMP Negeri 10 Padang. Informan dalam penelitian ini adalah kepala sekolah, guru, siswa dan beberapa anggota pramuka dengan menggunakan teknik purposive sampling. Jenis data dalam penelitian ini adalah data primer dan sekunder. Teknik pengumpulan data dengan cara observasi, wawancara dan studi dokumentasi. Alat pengumpulan data adalah peneliti sendiri dengan menggunakan pedoman wawancara, pedoman observasi dan studi dokumentasi. Uji keabsahan data dilakukan melalui triangulasi data.

\section{HASIL DAN PEMBAHASAN}

Kepedulian sosial siswa dalam mengamalkan nilai-nilai dasa darma Pramuka
Kepedulian merujuk pada suatu hubungan antara individu atau kelompok yang didasarkan pada perasaan moral atau kepercayaan yang dianut bersama serta diperkuat dengan pengalaman emosional bersama (Murniati, 2011:206). Kepedulian sosial yang dimaksud adalah perasaan bertanggung jawab atas kesulitan yang dihadapi orang lain dimana seseorang terdorong melakukan sesuatu untuk mengatasinya. Kepedulian itu tidak akan muncul dengan sendirinya tanpa adanya pembinaan dan pendidikan yang dilakukan secara terus-menerus sehingga menjadi suatu pembiasaan atau kebiasaan dalam kehidupan sehari-hari. Seorang dapat dikatakan peduli jika berlangsungnya suatu interaksi antara satu dengan yang lainnya. Interaksi sosial merupakan hubungan sosial yang dinamis, yang menyangkut hubungan antara orang perorangan, antara kelompok manusia, maupun antara orang perorangan dengan kelompok manusia (Soekanto, 2014:55).

Berdasarkan Anggaran Dasar dan Anggaran Rumah Tangga Gerakan Pramuka (AD/ART) Pasal 8 Ayat 1 Pendidikan Kepramukaan adalah proses pendidikan yang dilakukan di luar lingkungan sekolah dan di luar lingkungan keluarga dalam bentuk kegiatan menarik, menyenangkan, sehat, teratur, terarah, praktis. Kegiatan ini dilakukan di alam terbuka dengan prinsip dasar dan metode kepramukaan yang sasaran akhirnya adalah terbentuknya watak kepribadian dan akhlak mulia. Pendidikan kepramukaan dilakukan sebagai kegiatan ekstrakurikuler wajib pada pendidikan dasar dan pendidikan menengah yang wajib 
diikuti oleh seluruh peserta didik. Pendidikan kepramukaan dilaksanakan untuk menginternalisasikan nilai ketuhanan, kebudayaan, kepemimpinan, kebersamaan, sosial, cinta alam, dan kemandirian pada peserta didik (Permen No. 63 Tahun 2014).

Gerakan Pramuka merupakan suatu wadah atau organisasi yang bertujuan untuk membentuk manusia yang berkepribadian dan berwatak luhur serta sehat jasmani dan rohani, sehingga menjadi warga negara Indonesia yang berjiwa Pancasila yang mampu dan sanggup untuk menyelenggarakan pembangunan masyarakat, bangsa dan negara. Dalam gerakan pramuka ini sangat menjunjung tinggi dasa darma pramuka yang merupakan ketentuan moral atau tuntutan tingkah laku bagi seorang anggota pramuka. Pada dasarnya seorang anggota pramuka harus bisa mencerminkan sikap dan perilakunya yang baik sesuai dengan dasa darma pramuka dalam kehidupan sehari-harinya.

Sepuluh ketentuan moral dan tuntutan tingkah laku yang harus ada pada jiwa seorang anggota pramuka dikenal dengan dasa darma: (1) Takwa Kepada Tuhan Yang Maha Esa. Hal ini berpedoman kepada segala yang ada di bumi dan di langit semuanya adalah ciptaan Allah Swt, baik yang terlihat maupun yang tidak terlihat. Manusia diciptakan oleh Allah Swt untuk beribadah kepada-Nya. Untuk itu sebagai makhluk kita harus patuh dan taat terhadap perintah dan menjauhkan diri dari segala laranganNya, (2) Cinta alam dan kasih sayang sesama manusia. Manusia sebagai makhluk pribadi, juga disebut sebagai makhluk sosial. Artinya kita sebagai manusia tidak dapat hidup dengan sendirinya tanpa adanya bantuan orang lain, (3) Patriot yang sopan dan kesatriaan.

Sebagai anggota pramuka kita harus berperilaku dan bertindak dengan sopan karena sejatinya seorang pramuka itu akan menjadi contoh yang baik bagi orang-orang di sekelilingnya. Kesopanan itu adalah cerminan dari perilaku sehari-hari baik dalam berkata maupun berbuat, (4) Patuh dan suka bermusyawarah. Seorang anggota pramuka dalam situasi dan kondisi apapun wajib patuh dan taat terhadap aturan yang berlaku. Untuk mengambil atau melakukan suatu kebijakan dan keputusan perlu dimusyawarah terlebih dahulu sehingga apa yang diputuskan diterima dengan baik oleh anggota lainnya, (5) Rela menolong dan tabah. Seorang pramuka harus senantiasa rela berkorban dan memiliki jiwa tolong-menolong tanpa membeda-bedakan agama,ras dan suku yang didasari dengan hati yang ikhlas, tulus, dan tanpa mengharapkan balasan atau imbalan.

Seorang pramuka harus tabah dalam menghadapi berbagai tantangan, rintangan dan hambatan yang dialami selama melakukan kegiatan, (6) Rajin, terampil dan gembira. Seorang pramuka itu harus rajin melakukan sesuatu yang positif dan mengimplementasikan setiap apa yang didapat dalam pembinaan pramuka yang diikuti dengan terampil sehingga memberikan manfaat bagi diri sendiri dan orang lain. Mereka juga harus bekerja ikhlas melaksanakan tugas atau kegiatan dengan hati senang dan gembira, (7) Hemat, cermat dan bersahaja. Kegiatan pramuka bukanlah kegiatan yang 
membuang-buang waktu tapi kegiatan pramuka adalah salah satu kegiatan yang melatih kita untuk hidup hemat dengan memanfaatkan apa yang ada di alam dan lingkungan sekitar kita. Dalam kegiatan pramuka tidak membutuhkan banyak uang namun cukup memanfaatkan alam tanpa menghambur-bamburkan uang untuk hal yang tidak bermanfaat.

Dari kegiatan tersebut mengajarkan kita untuk hidup hemat dalam penggunaan kebutuhan hidup, cermat dalam pemanfaatkan apa yang ada dan bersahaja dengan alam serta tidak boleh sombong atau angkuh, (8) Disiplin, berani dan setia. Seorang anggota pramuka harus disiplin dalam segala hal yaitu disiplin dalam waktu, berbuat dan bertindak. Disiplin adalah kunci utama yang menjadikan kita lebih baik, baik dalam bertindak maupun dalam berperilaku. Seorang pramuka harus berani dalam menghadapi berbagai persoalan, seperti halnya berani berbuat, berani bertanggung jawab. Seorang pramuka harus setia terhadap janji-janji yang sesuai dengan dasa darma pramuka, (9) Bertanggung jawab dan dapat dipercaya. Seorang pramuka harus bisa betanggungjawab atas apa yang dilakukan sehingga dapat dipercayai oleh orang lain, (10) Suci dalam pikiran, perkataan dan perbuatan. Seorang pramuka harus memiliki pemikiran yang jernih tanpa ada iri dan dengki terhadap sesama, berpikir sebelum berbicara sehingga tidak menyakitkan bagi orang lain serta berbuat sesuai dengan nilai-nilai dan norma yang berlaku.

Berdasarkan hasil penelitian di lapangan menunjukan bahwa siswa sudah mengamalkan dasa darma pramuka dalam kehidupannya seharihari. Semua siswa terlihat sudah melaksanakan kewajibannya menunaikan sholat, saling mengasihi dan menyayangi, saling menghormati dan menghargai, patuh terhadap aturan dan perintah yang diberikan, sopan terhadap orang yang lebih besar seperti guru, serta memiliki sikap dan perilaku yang baik terhadap sesamanya. Oleh sebab itu sebagai seorang pramuka harus menjunjung tinggi dasa darma pramuka yang harus diamalkan dan diterapkan dalam kehiduapn sehari-hari.

\section{Aktivitas kepramukaan dalam meningkatkan nilai-nilai kepedulian sosial siswa}

Aktivitas adalah suatu proses kegiatan yang diikuti dengan terjadinya perubahan tingkah laku, sebagai hasil interaksi dengan lingkungan. Aktivitas artinya kegiatan atau keaktifan, jadi segala sesuatu yang dilakukan atau kegiatan-kegiatan yang terjadi baik fisik maupun nonfisik, merupakan suatu aktivitas (Mulyono, 2001: 26). Pramuka merupakan proses pendidikan di luar lingkungan sekolah dan di luar keluarga dalam bentuk kegiatan menarik, menyenangkan, sehat, teratur, terarah, praktis yang dilakukan di alam terbuka yang sasaran akhirnya adalah untuk pembentukan watak, akhlak dan budi pekerti luhur (Gunawan, 2012).

Aktivitas-aktivitas dalam kegiatan pramuka ini dapat membina kepedulian sosial siswa ke arah yang lebih baik. Dalam kegiatan-kegiatan pramuka, di dalamnya mengandung nilai-nilai yang mampu meningkatkan kepedulian sosial siswa seperti: kegiatan upacara, berkemah, tali- 
Aktivitas dalam hiking atau penjelajahan merupakan suatu kegiatan di alam terbuka yang menarik, menyenangkan dan menantang yang dapat mengembangkan kecintaan mereka kepada alam dan menambah wawasan tentang lingkungan.

Dalam kegiatan pejelajahan ini terjadi proses penerapan dan pengembangan nilai-nilai kepemimpinan, demokrasi, kekompakan kerja, kematangan berfikir, kemandirian, percaya diri, keterampilan dan ketangkasan, administrasi dan pembagian tugas, pengetahuan dan pengalaman (Damrah,2017:90-91). Nilai-nilai yang terkandung dalam kegiatan hiking ini yaitu peduli lingkungan, kebersamaan, cinta alam, tanggung jawab, tolong menolong dan lainnya. Nilai ini yang harus ada pada setiap jiwa seorang anggota pramuka sehingga dapat diaplikasikan dalam kehidupan sehari-harinya sebagai bentuk dari pengamalan dasa darma pramuka.

\section{KESIMPULAN}

Kepedulian sosial siswa dalam mengamalkan nilai-nilai dasa darma pramuka, berdasarkan pembahasan dan hasil penelitian dapat disimpulkan bahwa siswa sudah mengamalkan dasa darma pramuka dengan baik dalam kehidupan sehari-harinya di lingkungan sekolah. Siswa sudah menunjukan ketaqwaannya dengan selalu mendirikan sholat dan berbuat baik kepada sesama. Selain itu siswa menunjukan sikap dan tingkah laku yang baik sopan patuh dan taat dengan saling tolong-menolong, menghormati dan menghargai baik orang yang lebih tua maupun yng lebih muda. Namun ada juga siswa yang belum bisa sepenuhnya mengamalkan nilai-nilai dasa darma dengan baik. Hal tersebut dapat terjadi karena belum semua siswa memahami dasa darma.

Aktivitas kepramukaan dalam meningkatkan nilai-nilai kepedulian sosial siswa terlihat dalam setiap kegiatan yang dilaksanakan. Pada kegiatan upacara, terdapat nilai kerjasama. Dalam kegiatan tali-temali terdapat nilai kerjasama dan kreatifitas. Dalam kegiatan barisberbaris terdapat nilai persatuan dan kekompakan. Pada kegiatan berkemah terdapat banyak sekali nilai-nilai sosial yang diberikan kepada siswa yaitu kebersamaan, kekeluargaan, tolongmenolong, kerjasama, peduli alam dan lingkungan. Untuk itu diharapkan kegiatan pramuka yang dilakukan di sekolah mampu memberikan pendidikan dan pembinaan sikap peduli sosial siswa dengan lebih baik lagi. Sehingga semua nilai-nilai dasa darma pramuka teraplikasikan dengan baik dalam kehidupan sehari-hari dan dapat diterapkan dalam setiap kegiatan.

\section{DAFTAR PUSTAKA}

Asnawi, Ibnu Hanif \& Triwahyuningsih.2014. Peranan Pembina Pramuka dalam Mengembangkan Karakter Kepemimpinan Siswa di SMP Negeri 3 Depok Sleman. Jurnal Citizenship Vol.3, No.2, Januari 2014. Hal. 95-104

A.Tabi'in. 2017. Menumbuhkan Sikap Peduli Pada Anak Melalui Interaksi Kegiatan Sosial. Ijtimaiyah, Volume 1, Nomor 1, Juli-Desember 2017. 
$60 \mid$ pembinaan sikap..

Anton, M, Mulyono.2001. Aktivitas Belajar. Bandung. Yrama.

Damrah.2017. Buku Ajar Kepramukaan FIK UNP. Padang : UNP Press.

Erliani Sa'adah.2016. Peran Gerakan Pramuka Untuk Membentuk Karakter Kepedulian Sosial Dan Kemandirian (Studi Kasus Di SDIT Ukhwah Dan MIS AnNuriyyah

Banjarmasin).MUALLIMUNA: Jurnal Madrasah Ibtidaiyah, Volume 2, Nomor 1, Oktober 2016.

Gunawan, Heri. 2012. Pendidikan Karakter, Konsep Dan Implementasi. Bandung. Alfabeta.

Murniati Baiq. 2011. Pengaruh Pendekatan Analisis Nilai dalam Pembelajaran IPS terhadap Sikap Kepedulian Sosial Peserta Didik. Edisi Khusus No. 2 Agustus 2011.

Soekanto, Soerjono. 2014. Sosiologi Suatu Pengantar. Jakarta: PT RajaGrafindo Persada.

Undang-Undang No. 12 Tahun 2010 Tentang Gerakan Pramuka.

Peraturan Menteri Pendidikan dan Kebudayaan Nomor 63 Tahun 2014 tentang Pendidikan Kepramukaan.

Keputusan Kwatir Nasional Gerakan Pramuka Nomor 203 Tahun 2009 tentang Anggaran Rumah Tangga Gerakan Pramuka (ARTGP).

Keputusan Presiden Republik Indonesia Nomor 24 Tahun 2009 Tentang Pengesahan Anggaran Dasar Gerakan Pramuka(ADGR). 